\title{
Patterns of human evolution in northeast Asia with a particular focus on Salkhit
}

Damdinsuren Tseveendorj ${ }^{a}$, Byambaa Gunchinsuren ${ }^{a}$, Eregzen Gelegdorj ${ }^{a}$, Seonbok ${ }^{b}{ }^{b}$, Sang-Hee Lee $*^{c}$

${ }^{a}$ Institute of Archaeology, Mongolian Academy of Sciences, Ulaanbaatar 51, Mongolia

${ }^{\mathrm{b}}$ Department of Archaeology, Seoul National University, Seoul 151-742, Korea

c Department of Anthropology, University of California at Riverside, Riverside, California 92521-0418, USA

* Corresponding author: shlee@ucr.edu

\section{Abstract}

Despite the well published mixture of archaic and modern features in fossil hominins, a presence of archaic features is still used as a basis for a claim of an archaic specimen. In this paper, the archaic appearance of a hominin fossil specimen from Salkhit, Mongolia, is examined to ask if Salkhit looks archaic because it is an archaic specimen like a classic Homo erectus. The morphology and metrics of the Salkhit skullcap was compared with Middle and Late Pleistocene hominin fossils from Zhoukoudian: Locality 1 and Upper Cave. Results show that the archaic features that Salkhit shares with the Locality 1 sample are also shared with the other sample, Upper Cave. On the basis of metrics, Salkhit is intermediate between the Locality 1 and the Upper Cave specimens. Salkhit is different from the Middle Pleistocene materials in the same way later hominins differ from the Middle Pleistocene sample, in having a broader frontal and thinner supraorbital 
region. This may reflect encephalization and gracilization, a modernization trend found in many places. Results of this paper are not compatible with the null hypothesis that Salkhit is like a member of the Zhoukoudian Homo erectus sample. Archaic features may have different explanations: they can be diagnostic features of an archaic species, or regionally predominant features. It is concluded that the latter explains the archaic features of Salkhit.

Keywords: human evolution; paleoanthropology; archaic; morphology; Salkhit; northeast Asia

\section{Introduction}

It is well documented in paleoanthropology literature that archaic features appear in archaic specimens as well as later specimens in a mixture of archaic and modern features (Wolpoff, 1999). However, it still is a practice often found that a presence of an archaic feature alone provides a basis for a diagnosis of a membership in an archaic species.

A skullcap found in Salkhit, Mongolia $\left(48^{\circ} \mathrm{N}, 112^{\circ} \mathrm{E}\right)$ was given a new genus Mongolanthropus, based on its archaic morphology, with a suggested date of 800,000 years, based on a woolly rhinoceros discovered in the vicinity (Tseveendorj et al., 2006). The woolly rhinoceros, however, was not found together with the hominin fossil, and therefore it is uncertain that they are contemporaneous. Furthermore, woolly rhinoceros has a lengthy tenure of appearance throughout Pleistocene (Boeskorov, 2012) that the presence of the fossil species alone is not a reliable or accurate biostratigraphic marker of time. 
In the absence of chronometric dating, the various dates that have been suggested range from early Middle Pleistocene (Bae, 2010; Tseveendorj et al., 2006) to terminal Late Pleistocene (Kaifu and Fujita, 2012). Coppens et al. (2008) used a multidimensional scaling method to analyze the mixture of archaic and modern features, and concluded that the Salkhit skullcap clusters with Neandertals, Homo erectus, archaic Homo sapiens, but ruled out modern Homo sapiens. Coppens et al's study focused on the possible affinity between Salkhit and the Neandertals. If so, it would extend the Neandertal distribution further east of Okladnikov Cave, currently the easternmost Neandertal site (Bae, 2010; Derevianko, 2011).

The Salkhit specimen is unlikely to be as old as 800,000 years. It could be of Middle Pleistocene age: hominins left evidence from the late Early Pleistocene in what is now the mainland Asia continent and south Asia (Pappu et al., 2011; Zhu et al., 2003; Zhu et al., 2001; Zhu et al., 2008; Zhu et al., 2004). Hominin presence is found in Europe as early as $1 \mathrm{Ma}$ (Dennell, 2003). Given the long history of hominin occupation in Asia and Europe, this paper considers the possibility that Salkhit is Middle Pleistocene in age.

\section{Methods and Materials}

The Salkhit skullcap is compared with the only hominin sample of Middle and Late Pleistocene specimens from the geographic vicinity: Zhoukoudian Locality 1 and Upper Cave. Other hominin fossils are isolated individual finds. Because only the skullcap is preserved, comparisons were limited, based on morphology and metrics. Observation and measurements for the Salkhit skullcap were taken on the original specimen as well as on a cast. Photographs are from the original specimen (Figure 1). Comparison with other 
specimens was done with casts only.

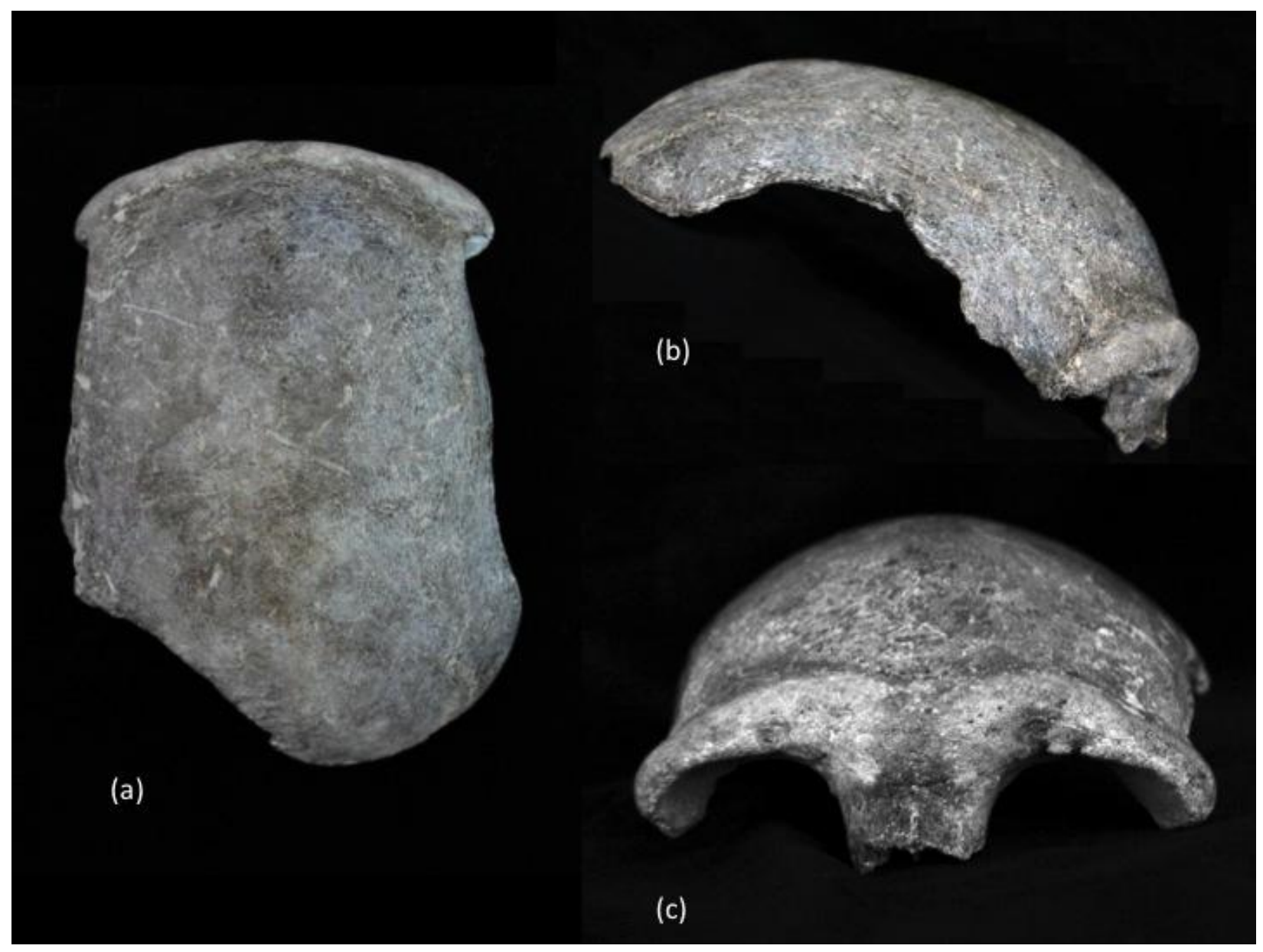

Figure 1. Salkhit skullcap: (a) superior view; (b) lateral view; (c) anterior view

\section{Results and Discussion}

\subsection{Morphological Comparison}

At first glance, Salkhit shares similarity in several morphological traits with Locality 1. Salkhit has a weak sagittal keel on the frontal between glabella and bregma, but there is no prebregmatic eminence. However, the sagittal keel in Salkhit is not as prominent as in the Zhoukoudian specimens, most prominently expressed in Zhoukoudian XII, and 
comparably weak in Upper Cave 101.

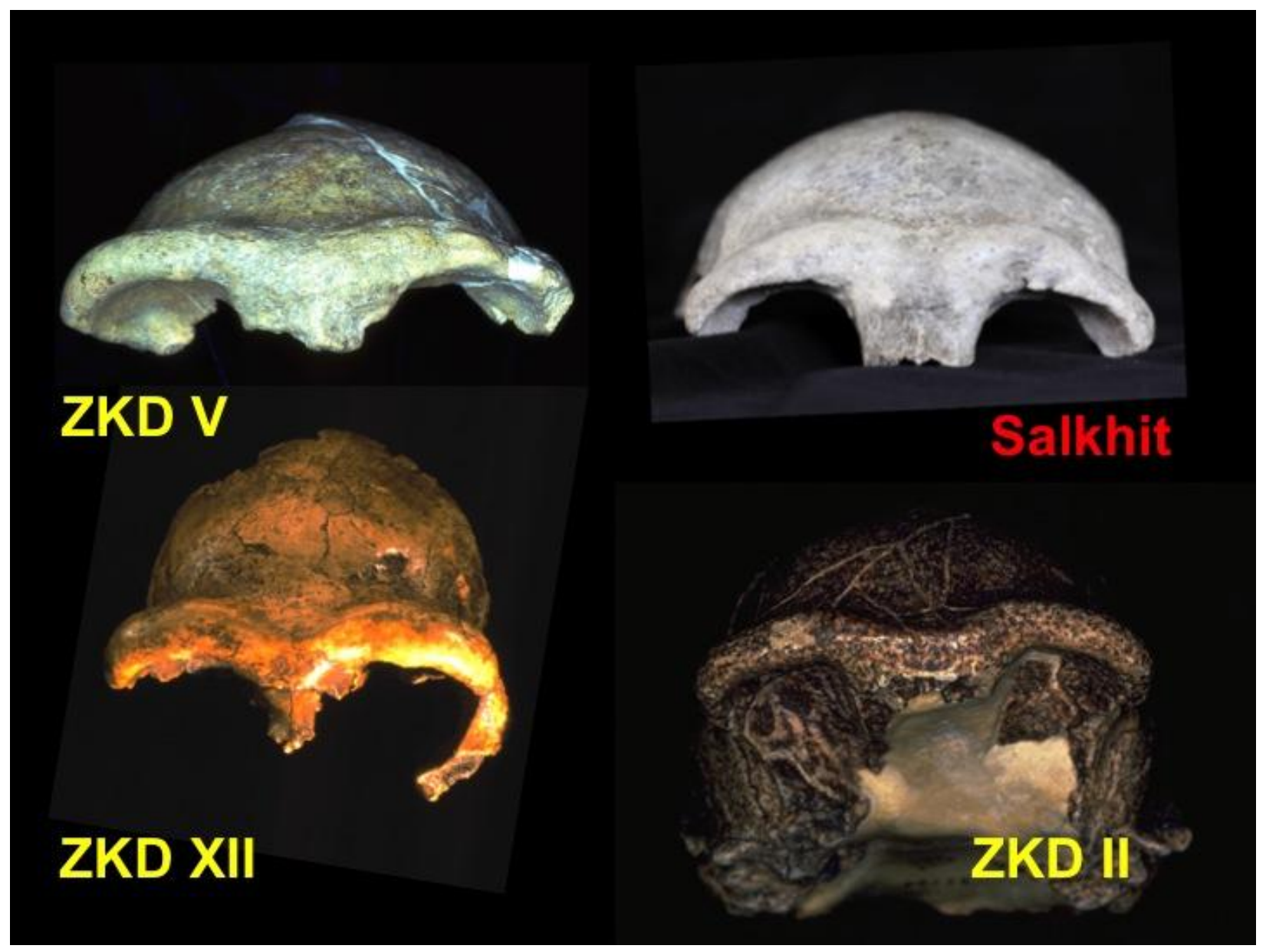

Figure 2. Anterior views showing variation in supraorbital regions of Salkhit and Locality 1 specimens. The specimens are not in the same orientation.

The supraorbital region of the Salkhit skullcap plays a major role in giving an archaic appearance of the specimen (Figure 2). Seen from the front, the torus forms an M- or a seagull-shape, contributed by the pinching of the glabellar torus. The glabellar torus rises above the nasal bridge and is thinner in supero-inferior height than the supraorbital torus in Salkhit and in some Locality 1 crania (especially in Skull XII (L3)) and Upper Cave 
(UC 101), but not in others (such as Skull V).

The medial portion of the supraorbitals has greater supero-inferior thickness than the lateral portion, but there is no difference in the anterior projection between the medial and the lateral portions. The lateral portion of the supraorbital region turns into a slight knob at the lateral ends in both Salkhit and Locality 1 sample; however, the thickening at the lateral ends of the supraorbitals is not comparable to that seen in the Zhoukoudian sample which has a knobbed look. In Salkhit the lateral torus is continuous, but more gracile than the medial portion; in Locality 1, the lateral portion is thicker and smoother, without any interruption in the surface of the torus; the supraorbital torus reaches maximum thickness toward the lateral end to form a knob.

In Salkhit, there is a weak supraorbital sulcus that does not continue across the midline. In contrast, in the Locality 1 sample, the sulcus is an actual gutter that is dipping (as in Skull XII) or shallow and broad (as in Skull V), and is most pronounced where the supraorbital torus is the thickest.

In Salkhit and Locality 1 crania, the supraorbitals are different morphologically between the medial and the lateral halves. The contrast between the medial and the lateral portions of the supraorbital region of Salkhit takes a different pattern in the Locality 1 sample. In the Locality 1 sample, the medial and lateral portions do not have an incisura. The medial portion is laterally marked by a supraorbital process (most prominent in Skull $\mathrm{X})$. There is an incisura in Salkhit, which is noted as a modern human feature by Weidenreich (1943 p. 29). A supraorbital foramen is absent in the Locality 1 sample, while a double-notch is in the location of the supraorbital process in Skull XII.

When Salkhit is compared with the three specimens in Upper Cave, two specimens, 
UC 102 and UC 103, have a superciliary arch and do not have a supraorbital torus. UC 101 shows a surprising similarity with Salkhit in many aspects. In both Salkhit and UC 101, the supraorbital bar continues throughout the supraorbtial region; the medial portions are thicker than the lateral portions; the supraorbital torus thickens at the lateral end, resulting in a slightly knobbed look. There is a weak but discernible groove that separates the torus into two components, medial and lateral. In Salkhit, the medial and the lateral portions of the left supraorbital are demarcated by a faint groove, which is weaker than is observed in UC 101; it is almost an uninterrupted continuation of a torus on the right side, but it cannot be ascertained due to a possible distortion from the healed wound.

In the parietals, there is no keel on the sagittal suture of Salkhit, in contrast to the Locality 1 specimens. In both Salkhit and UC 101, there is a raised ridge that runs parallel to the sagittal suture, and the ridges follow the suture, diverging as they swerve posterior and inferior. This feature is also seen in Locality 1 Skull XII.

In Salkhit, the nasofrontal and frontomaxillar sutures form a continuous, horizontal course, similar to the case in Locality 1 Skull XII. In Skull XII, however, nasal bones are broad, with no difference between the upper breadth and the middle breadth, while in Salkhit, the nasals have a pinched shape. Salkhit has a low nasal angle (height of the saddle made from two nasals); Upper Cave specimens have a higher nasal angle than Salkhit.

\subsection{Metric Comparison}

In metric measurements, some variables show Salkhit to be in-between Locality 1 and Upper Cave (Figure 2), while other variables are non-informative. Due to the small 
sample size, statistical tests were not performed.

In frontal breadth, Salkhit at $98.06 \mathrm{~mm}$ is greater than the range of the Locality 1 sample (X, XI, XII, V), from 85.7 to $89 \mathrm{~mm}($ mean $=87.5 \mathrm{~mm})$, and smaller than the range of the Upper Cave sample (from 102 to $109.3 \mathrm{~mm}$ ). Frontal length is not informative, as the range in the Locality 1 sample encompasses Salkhit and Upper Cave specimens (Table 1). However, the frontal curvature index $(=(\operatorname{arc} / \mathrm{chord}) * 100)$ of Salkhit (109.12) is larger than the Zhoukoudian values.

Table 1. Frontal metric data (in $\mathrm{mm}$.). Osteometric points $\mathrm{ft}=$ frontotemporale $; \mathrm{gl}=$ glabella; br = bregma . M9 refers to the osteometric point number 9 using the Martin numbering system (Martin and Saller, 1957).

\begin{tabular}{|l|r|r|r|r|}
\hline & ft-ft (M9) & gl-br arc & gl-br chord & curvature \\
\hline Salkhit & 98.06 & 117 & 107.22 & 109.12 \\
\hline ZKD10 & 89 & 120.5 & 114.7 & 105.06 \\
\hline ZKD11 & 85.7 & 114 & 105.4 & 108.16 \\
\hline ZKD12 & 87.9 & 110 & 107 & 102.80 \\
\hline ZKD5 & 87.4 & 122 & 116.1 & 105.08 \\
\hline ZKD2 & 84 & 115 & 111.5 & 103.14 \\
\hline UC101 & 109.30 & 117.50 & 108.80 & 108.00 \\
\hline UC102 & 104.00 & 119.50 & 111.00 & 107.66 \\
\hline UC103 & 102.00 & 113.00 & 104.00 & 108.65 \\
\hline
\end{tabular}




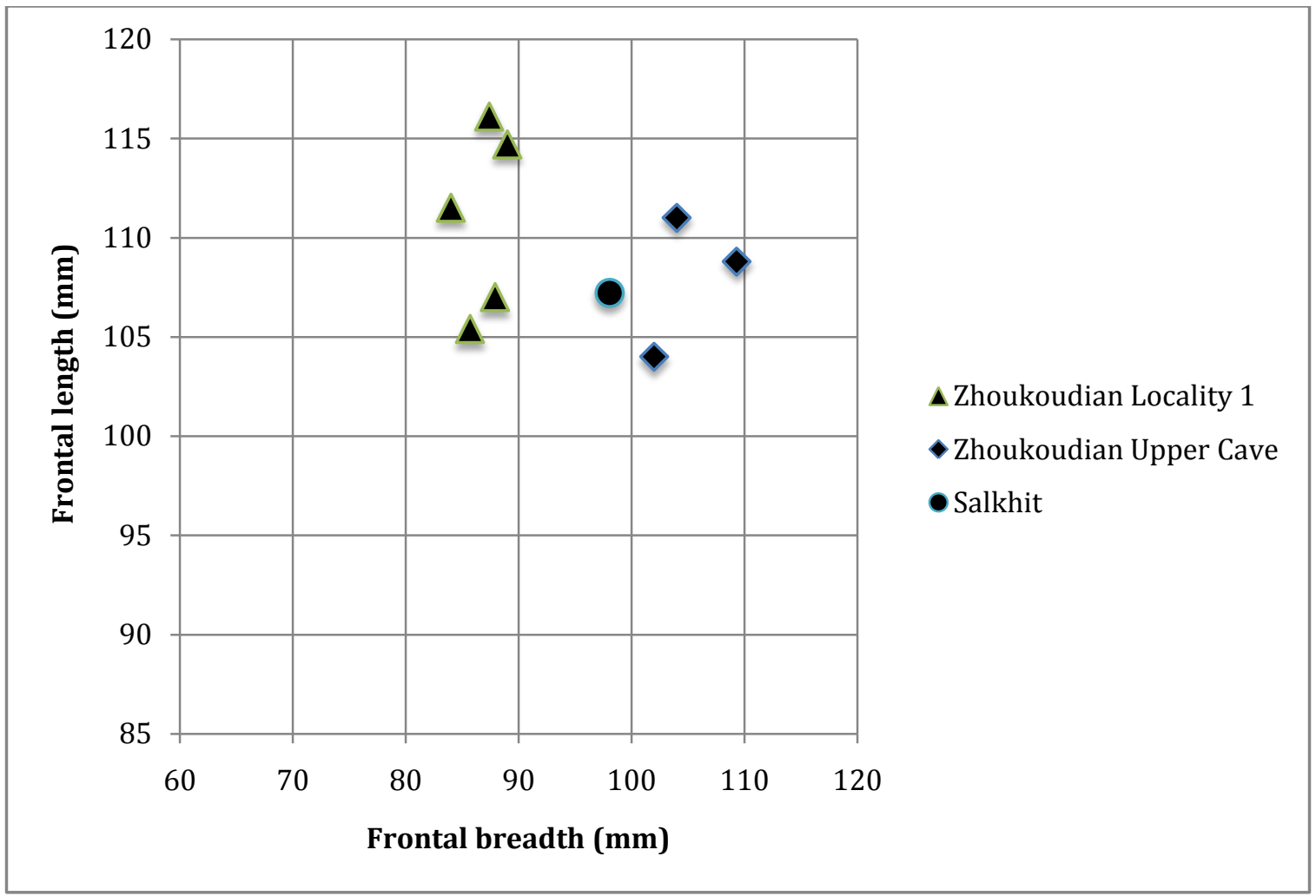

Figure 2. Scatterplot of frontal length (chord) versus frontal breadth. Salkhit is between the Zhoukoudian Locality 1 specimens and the Zhoukoudian Upper Cave specimens in frontal breadth.

\subsection{Discussion}

The case of Salkhit is another example where an archaic membership is suggested based on an archaic or a robust appearance. The results of this paper provide support that archaic features do not necessarily mark the specimen to be from an archaic time. An archaic morphology may be an indication of an archaic ancestry, rather than an archaic time period.

The similarities that Salkhit share Zhoukoudian Locality 1 are the same ones that it shares with Zhoukoudian Upper Cave. Such features, for example, sagittal keel, are examples of regionally persistent features (Rosenberg and Wu, 2013), found in Dali and Ziyang (Wolpoff, 1999) in addition to Salkhit and Zhoukoudian. That a specimen such as Salkhit shows such a trait is not supportive of its antiquity; rather, it is compatible with its regional origin. Despite the archaic impression from the supraorbital region, Salkhit is 
otherwise more gracile than the Zhoukoudian Homo erectus sample; Salkhit's cranial thickness, measured at bregma $(6 \mathrm{~mm})$ is thinner than the Locality 1 range $(7-10.6 \mathrm{~mm})$.

A similar example of archaic features not being a marker for an archaic specimen is also found in the case of Ceprano, of which the initial date of 1 myr was compatible with its archaic features (Manzi, 2004); however, its date is now considered to be half as old, 460 kyr (Muttoni et al., 2009), which puts the archaic features of Ceprano in a new light (Dennell et al., 2011). Ceprano is a member of a population that exhibits archaic features due to ancestry, and not because of an archaic date.

The morphology of Salkhit supraorbital region can be described as intermediate between a supraorbital torus and a superciliary arch. Whether it is a supraorbital torus or superciliary arch is somewhat irrelevant in the investigation into affinity: the mere presence of torus does not define Salkhit as an archaic specimen. A supraorbital torus is not exceptional or unusual among extant, recent humans, such as Mladeč (Frayer et al., 2006), Willandra Lake Hominid 50 and several from the Coobool Creek sample (Thorne and Wolpoff, 1981) being only a few of many examples. M-shaped supraorbitals are also found in specimens from Middle and Late Pleistocene, and also in Australians as recent as WLH 50 (Durband and Westaway, 2013). Considering the recent discovery of Denisovan genetic signal in southeast Asia while almost absent in northeast Asia (Reich et al., 2010; Reich et al., 2011; Skoglund and Jakobsson, 2011), the shared similarity between Salkhit and the recent Australians points toward a future research.

Salkhit is different from the Zhoukoudian Homo erectus sample in the same ways that modern humans are different from Homo erectus, namely in the expansion of brain size and gracilization. Metric variables suggest a trend with a direction. While frontal length measurements do not change, as all specimens show values within the range defined by the Zhoukoudian Locality 1 sample, there is a distinct pattern in the frontal breadth measurements. Salkhit is in-between the Zhoukoudian Locality 1 and the Upper Cave specimens, suggesting an expansion in frontal breadth. This encephalization trend reflects what is found throughout the Pleistocene (Lee and Wolpoff, 2002). A corollary to that observation is that Salkhit has less postorbital constriction than the Zhoukoudian sample. The timing of cranial increase in frontal breadth is compatible with gracilization and encephalization, the two trends that are observed globally throughout Late Pleistocene 
human evolution (Wolpoff, 1999).

The morphological configuration of Salkhit is quite compatible with the date mentioned in the magazine interview (Crooson, 2010), 27,000 years old. Although Salkhit may not look like a member of Zhoukoudian Homo erectus, it is still possible that Salkhit is a Middle Pleistocene specimen. This has particular relevance as questions arise whether Zhoukoudian is representative of Middle Pleistocene Asian Homo erectus: Antón argues that Zhoukoudian is an exception rather than a rule for Asian Homo erectus (Antón, 2003) . Considering that more research is showing early Homo to be more variable that was thought before (Lordkipanidze et al., 2013; Van Arsdale and Wolpoff, 2012), a wider range of specimens are necessary to provide a comparative perspective.

\section{Acknowledgements}

We thank Robin Dennell and Gao Xing for the invitation to participate in this special issue. We give heartfelt gratitude to Yves Coppens (Centre National de Recherche Scientifique) and Milford Wolpoff (Univeristy of Michigan) for their infinite generosity. Robin Dennell and two reviewers provided generous help in strengthening this paper. This study was supported by National Geographic Society (W35-08), National Science Foundation (0803410), Seoul National University, and the University of California at Riverside.

\section{References}

Antón, S.C., 2003. Natural history of Homo erectus. American Journal of Physical Anthropology, Supplement: Yearbook of Physical Anthropology 122, 126-170.

Bae, C.J., 2010. The late Middle Pleistocene hominin fossil record of eastern Asia: Synthesis and review. American Journal of Physical Anthropology 143, 75-93.

Boeskorov, G.G., 2012. Some specific morphological and ecological features of the fossil woolly rhinoceros (Coelodonta antiquitatis Blumenbach 1799). Biology Bulletin 39, 692707.

Coppens, Y., Tseveendorj, D., Demeter, F., Turbat, T., Giscard, P.-H., 2008. Discovery of an archaic Homo sapiens skullcap in Northeast Mongolia. Comptes Rendus Palevol 7, 51-60. 
Crooson, D.L., 2010. Vieus d'environ 20,000 ans l'homme de Salkhit a parlé. National Geographic 2010, 49-57.

Dennell, R., 2003. Dispersal and colonisation, long and short chronologies: how continuous is the Early Pleistocene record for hominids outside East Africa? Journal of Human Evolution 45, 421-440.

Dennell, R.W., Martinón-Torres, M., Bermúdez de Castro, J.M., 2011. Hominin variability, climatic instability and population demography in Middle Pleistocene Europe. Quaternary Science Reviews 30, 1511-1524.

Derevianko, A.P., 2011. The origin of anatomically modern humans and their behavior in africa and eurasia. Archaeology, Ethnology and Anthropology of Eurasia 39, 2-31.

Durband, A.C., Westaway, M.C., 2013. Perspectives on the origins of modern Australians, in: Smith, F.H., Ahern, J.C.M. (Eds.), Origins of Modern Humans: Biology Reconsidered, Second Edition. Wiley, New York, pp. 123-150.

Frayer, D.W., Jelínek, J., Oliva, M., Wolpoff, M.H., 2006. Aurignacian male crania, jaws, and teeth from the Mladeč Caves, Moravia, Czech Republic, in: Teschler-Nicola, M. (Ed.), Early Modern Humans at the Moravian Gate: The Mladeč Caves and their Remains. Springer, Wien, pp. 185-272.

Kaifu, Y., Fujita, M., 2012. Fossil record of early modern humans in East Asia. Quaternary International 248, 2-11.

Lee, S.-H., Wolpoff, M.H., 2002. Pattern of brain size increase in Pleistocene Homo (abstract). Journal of Human Evolution 42, A19-A20.

Lordkipanidze, D., Ponce de León, M.S., Margvelashvili, A., Rak, Y., Rightmire, G.P., Vekua, A., Zollikofer, C.P.E., 2013. A complete skull from Dmanisi, Georgia, and the evolutionary biology of early Homo. Science 342, 326-331.

Manzi, G., 2004. Human evolution at the Matuyama-Brunhes boundary. Evolutionary Anthropology 13, 11-24.

Martin, R., Saller, K., 1957. Lehrbuch der Anthropologie. Gustav Fischer Verlag, Stuttgart.

Muttoni, G., Scardia, G., Kent, D.V., Swisher, C.C., Manzi, G., 2009. Pleistocene magnetochronology of early hominin sites at Ceprano and Fontana Ranuccio, Italy. Earth and planetary science letters 286, 255-268. 
Pappu, S., Gunnell, Y., Akhilesh, K., Braucher, R.g., Taieb, M., Demory, F.B., Thouveny, N., 2011. Early Pleistocene presence of Acheulian hominins in South India. Science 331, 1596-1599.

Reich, D., Green, R.E., Kircher, M., Krause, J., Patterson, N., Durand, E.Y., Viola, B., Briggs, A.W., Stenzel, U., Johnson, P.L.F., Maricic, T., Good, J.M., Marques-Bonet, T., Alkan, C., Fu, Q., Mallick, S., Li, H., Meyer, M., Eichler, E.E., Stoneking, M., Richards, M., Talamo, S., Shunkov, M.V., Derevianko, A.P., Hublin, J.-J., Kelso, J., Slatkin, M., Pääbo, S., 2010. Genetic history of an archaic hominin group from Denisova Cave in Siberia. Nature 468, 1053-1060.

Reich, D., Patterson, N., Kircher, M., Delfin, F., Nandineni, Madhusudan R., Pugach, I., Ko, Albert M.-S., Ko, Y.-C., Jinam, Timothy A., Phipps, Maude E., Saitou, N., Wollstein, A., Kayser, M., Pääbo, S., Stoneking, M., 2011. Denisova admixture and the first modern human dispersals into Southeast Asia and Oceania. The American Journal of Human Genetics 89, 516-528.

Rosenberg, K.R., Wu, X., 2013. A river runs through it: modern human origins in East Asia, in: Smith, F.H., Ahern, J.C.M. (Eds.), Origins of Modern Humans: Biology Reconsidered, Second Edition. Wiley, New York, pp. 89-121.

Skoglund, P., Jakobsson, M., 2011. Archaic human ancestry in East Asia. Proceedings of the National Academy of Sciences 108, 18301-18306.

Thorne, A.G., Wolpoff, M.H., 1981. Regional continuity in Australasian Pleistocene hominid evolution. American Journal of Physical Anthropology 55, 337-349.

Tseveendorj, D., Batbold, N., Amgalantogs, T., 2006. Mongolanthropus was discovered in Mongolia. Studia Archeologica Instituti Archaeologici Academiae Scientiarum Mongolicae 23, 5-10 (in Mongolian).

Van Arsdale, A.P., Wolpoff, M.H., 2012. A single lineage in early Pleistocene Homo: Size variation continuity in early Pleistocene Homo crania from East Africa and Georgia. Evolution 67, 841-850.

Weidenreich, F., 1943. The skull of Sinanthropus pekinensis: A comparative study of a primitive hominid skull. Palaeontologia Sinica, New Series D 10.

Wolpoff, M.H., 1999. Paleoanthropology, Second ed. McGraw-Hill, New York. 
Zhu, R., An, Z., Potts, R., Hoffman, K.A., 2003. Magnetostratigraphic dating of early humans in China. Earth-Science Reviews 61, 341-359.

Zhu, R.X., Hoffman, K.A., Potts, R., Deng, C.L., Pan, Y.X., Guo, B., Shi, C.D., Guo, Z.T., Yuan, B.Y., Hou, Y.M., Huang, W.W., 2001. Earliest presence of humans in northeast Asia. Nature 413, 413-417.

Zhu, R.X., Potts, R., Pan, Y.X., Yao, H.T., L, L.Q., Zhao, X., Gao, X., Chen, L.W., Gao, F., Deng, C.L., 2008. Early evidence of the genus Homo in East Asia. Journal of Human Evolution 55, 1075-1085.

Zhu, R.X., Potts, R., Xie, F., Hoffman, K.A., Deng, C.L., Shi, C.D., Pan, Y.X., Wang, H.Q., Shi, R.P., Wang, Y.C., Shi, G.H., Wu, N.Q., 2004. New evidence on the earliest human presence at high northern latitudes in northeast Asia. Nature 431, 559-562. 